\title{
Cultivo in vitro de clones de Ananas comosus (L.) Merril cultivar 'Smooth Cayenne' em diferentes concentrações de macronutrientes
}

\author{
Vívian Tamaki $^{1,3}$, Helenice Mercier ${ }^{2}$ e Catarina Carvalho Nievola ${ }^{1}$
}

Recebido: 22.06.2006; aceito: 04.12.2006

\begin{abstract}
In vitro cultivation of cloned of Ananas comosus (L.) Merril cultivar 'Smooth Cayenne' using different macronutrients concentrations). Clones of Ananas comosus cultivar Smooth Cayenne were obtained from etiolated stem. The isolated nodes were cultivated for 90 days in macronutrient dilutions of Murashige \& Skoog (1962) (MS): 1/2, 1/5, 1/10, $1 / 60,1 / 100$ and the complete MS medium. After this period, from the 1/10 dilution the fresh and dry masses greatly reducing in the shoot. The same effect was observed in roots only at dilution $1 / 60$. The highest endogenous nitrate content was observed in plants cultivated in MS. However the concentration of pigments remained constant until the $1 / 5$ dilution, reducing significantly at higher dilutions. Our results suggested that plants of Ananas comosus variety Smooth Cayenne could be cultivated in vitro in an MS/5 dilution, without showing any significant difference in relation to the development of these plants cultivated in a complete MS medium.
\end{abstract}

Key words: Ananas comosus, bromeliad, chlorophyll, nitrate

RESUMO - (Cultivo in vitro de clones de Ananas comosus (L.) Merril cultivar 'Smooth Cayenne' em diferentes concentrações de macronutrientes). Clones de Ananas comosus cultivar Smooth Cayenne foram obtidos a partir do estiolamento caulinar. Os nós foram cultivados por 90 dias em diluições dos macronutrientes de Murashige \& Skoog (1962) (MS): 1/2, 1/5, 1/10, 1/ 60 e 1/100, além do MS completo. Após esse período observou-se que a partir da diluição 1/10, as massas fresca e seca diminuíram na parte aérea e nas raízes, essa redução ocorreu a partir da diluição 1/60. O maior conteúdo de nitrato endógeno foi encontrado nas plantas cultivadas em MS. Contudo, a concentração dos pigmentos manteve-se constante até a diluição 1/5, diminuindo nas diluições maiores. Os resultados mostram que plantas de Ananas comosus, cultivar Smooth Cayenne, podem ser cultivadas in vitro na diluição MS/5, sem apresentar diferenças significativas em relação ao desenvolvimento daquelas cultivadas no meio MS completo.

Palavras-chave: Ananas comosus, bromélia, clorofila, nitrato

\section{Introdução}

Ananas comosus (L.) Merril, é uma bromélia de grande importância para a agricultura nacional e internacional, sendo o Brasil um dos maiores produtores e consumidores do abacaxi (Margarido 1991, Manica 1999). O cultivo in vitro do abacaxizeiro tem apresentado vantagens em relação aos métodos de propagação tradicionais, pois permite a produção de cerca de 5.000 plantas em um ano partindo-se de uma única coroa (Zepeda \& Sagawa 1981), enquanto em lavoura são necessários cerca de 15 a 20 meses para se conseguir cerca de 8 novas mudas a partir de uma planta (Devi 1997, Manica 1999). O estabelecimento do cultivo in vitro do abacaxizeiro a partir do isolamento de gemas provenientes de uma planta adulta emprega, na maioria das vezes, meios nutritivos adicionados de reguladores de crescimento vegetal (Mathews \& Rangan 1979, DeWald et al. 1988, Hirimburegama \& Wijesinghe 1992, Guerra et al. 1999, Macedo, et al. 2003, Barboza, et al. 2004). Kiss et al. (1995) descreveram um método para a micropropagação do abacaxizeiro baseado na utilização de nós retirados de plantas estioladas in vitro. Essa metodologia apresenta algumas vantagens em comparação às culturas iniciadas a partir de gemas axilares de coroas, pois os explantes provenientes das plantas estioladas já são assépticos e, portanto, não necessitam serem submetidos a processos de desinfestação, nem sempre eficazes. Todavia, o

1. Instituto de Botânica, Caixa Postal 3005, 01061-970 São Paulo, SP, Brasil

2. Universidade de São Paulo, Instituto de Biociências, Departamento de Botânica, Caixa Postal 11461, 05422-970 São Paulo, SP, Brasil

3. Autor para correspondência: vtamaki@uol.com.br 
método de Kiss et al. (1995) propõe a utilização de reguladores de crescimento no meio de cultivo, cujo emprego tem sido associado à indução de variações somaclonais (Pierik 1987, Zaffari et al. 2002, Joyce et al. 2003). Essas alterações não são desejáveis quando se visa obter lotes homogêneos de plantas com fenótipos selecionados, como é o caso do cultivar Smooth Cayenne do abacaxizeiro.

O meio de cultura freqüentemente utilizado para o cultivo in vitro do abacaxizeiro é o de Murashige \& Skoog (1962) (MS) adicionado de reguladores de crescimento (Zepeda \& Sagawa 1981, Rangan 1984, DeWald et al.1988, Guerra et al. 1999, Canto et al. 2004). Embora o meio MS completo seja o mais utilizado em cultura de tecidos vegetais (Caldas et al. 1998), para algumas espécies uma diluição dos macronutrientes desse meio pode ser mais indicada. Certas bromélias, como a espécie Pitcairnia flammea, não sobrevivem na presença de concentrações de nitrato maiores que $4 \mathrm{mM}$ (Nievola 1997). Da mesma forma, a espécie Aechmea nudicaulis apresentou maior crescimento na concentração de 7,5 mM de nitrogênio (Grossi 2000), ou seja, quantidades bem inferiores àquelas presentes na formulação do MS original. A utilização de diluições dos macronutrientes do meio MS tem propiciado o desenvolvimento satisfatório de várias espécies vegetais, dentre elas, de algumas bromélias (Mercier \& Kerbauy 1992, Mercier \& Kerbauy 1994, Vinterhalter \& Vinterhalter 1994, Pickens et al. 2003).

Parâmetros de crescimento, assim como certos compostos nitrogenados têm sido utilizados como indicadores da necessidade de adubação em espécies de monocotiledôneas (Argenta et al. 2001). Em Zea mays o conteúdo de clorofila tem sido parâmetro importante na avaliação da nutrição nitrogenada (Argenta et al. 2004), assim como em Ananas comosus, no qual a diminuição do conteúdo de pigmentos fotossintéticos foi relacionada à diminuição da disponibilidade de nitrogênio (Tamaki 2003).

Este trabalho teve por objetivo comparar o crescimento e as quantidades endógenas de pigmentos fotossintéticos e nitrato entre plantas clonadas de Ananas comosus cultivar Smooth Cayenne, cultivadas em diferentes diluições dos macronutrientes do meio MS, tendo em vista que a possibilidade de utilizar meios de cultura mais diluídos, sem prejudicar o desenvolvimento das plantas, pode trazer uma economia bastante desejável a um laboratório de micropropagação.

\section{Material e métodos}

Clonagem de plantas de A. comosus - Esse estudo foi realizado utilizando-se plantas clonadas de A. comosus cultivadas in vitro na ausência de reguladores de crescimento. A clonagem foi iniciada a partir de uma única planta de A. comosus cultivar Smooth Cayenne cultivada in vitro. Quando essa possuía cerca de $6,5 \mathrm{~cm}$ de altura, suas folhas foram cortadas, restando apenas o eixo caulinar envolvido pelas bases foliares. O eixo caulinar foi transferido para frasco de vidro com capacidade para $500 \mathrm{~mL}$, o qual continha $70 \mathrm{~mL}$ de meio de cultura MS geleificado (0,6\% ágar). Esse eixo se desenvolveu durante dois meses na ausência de reguladores de crescimento e no escuro, visando ao estiolamento caulinar (Figura 1). A partir do caule estiolado foram isolados cerca de 7 nós, que originaram, cada um deles, uma nova planta. Estas, após seis meses de crescimento, foram submetidas novamente à condição de escuro contínuo, estiolando por 2 meses. Assim, novas plantas foram originadas (Figura 1). Esse processo foi repetido até a obtenção de cerca de 700 nós no total.

Cultivo nas diferentes diluições dos macronutrientes do meio MS - Os nós obtidos na fase de estiolamento foram isolados e transferidos por 90 dias para frascos de $250 \mathrm{~mL}$ de capacidade, contendo $70 \mathrm{~mL}$ de meio geleificado ( $0,6 \%$ ágar). Foram testadas as seguintes diluições de macronutrientes do meio MS: 1/2 (MS/2), $1 / 5$ (MS/5), $1 / 10$ (MS/10), 1/60 (MS/60) e 1/100 (MS/100). Todos esses tratamentos continham 3\% sacarose, $0,1 \mathrm{mg} / \mathrm{L}$ de tiamina, $100 \mathrm{mg} / \mathrm{L}$ mio-inositol e a concentração original dos micronutrientes do meio MS (Murashige \& Skoog 1962). O pH foi acertado para 5,8. Como controle, empregou-se a composição normal de macronutrientes do meio MS. Foram utilizados cinco frascos por tratamento, contendo 10 nós em cada um deles. As 50 plantas obtidas em cada diluição foram utilizadas para as quantificações de massas fresca e seca da parte aérea e do sistema radicular e para as análises de nitrato e pigmentos (clorofilas a e b e carotenóides) presentes nos eixos caulinares.

Quantificação das massas fresca e seca - Foram analisadas a quantidade de massa fresca e seca dos eixos caulinares e das raízes de 10 plantas provenientes de cada tratamento. A massa seca foi mensurada após os eixos caulinares e raízes terem sido mantidos em estufa a $60{ }^{\circ} \mathrm{C}$, até a obtenção de massa constante. 


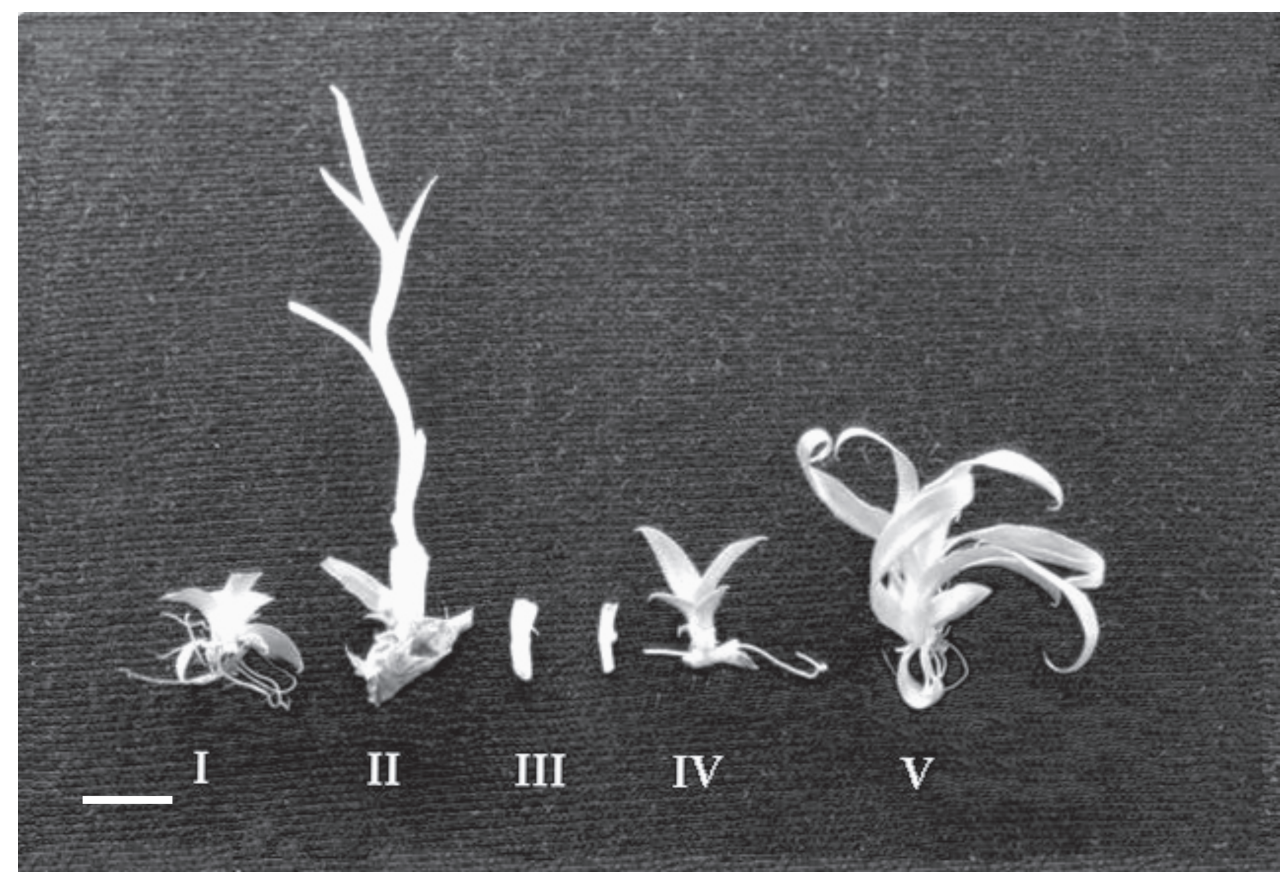

Figura 1. Seqüência de etapas para a obtenção dos clones de Ananas comosus variedade Smooth Cayenne: I - planta cultivada in vitro por 6 meses na presença de luz cujas folhas foram cortadas; II - planta estiolada obtida após dois meses de cutivo in vitro no escuro; III - dois segmentos nodais isolados (a partir de II); IV - planta obtida a partir do desenvolvimento da gema axilar (a partir de III); $\mathrm{V}$ - planta após três meses de cultivo in vitro. Barras das escalas $=1 \mathrm{~cm}$.

Para cada diluição foram utilizadas 10 plantas. As 40 plantas restantes foram usadas para as análises bioquímicas descritas a seguir.

Quantificação dos conteúdos endógenos de $\mathrm{NO}_{3}^{-}$Os eixos caulinares provenientes de 40 plantas foram coletados cerca de 4 horas após o início do período de luz, segundo indicações descritas em Nievola \& Mercier (2001). Esses eixos foram fragmentados em pequenas porções que foram misturadas, amostradas ( $1 \mathrm{~g}$ de massa fresca) e acondicionadas em pacotes de papel alumínio. Esses foram estocados a $-20{ }^{\circ} \mathrm{C}$ até o momento das análises de determinação de nitrato. O conteúdo de cada amostra ( $1 \mathrm{~g}$ de massa fresca congelada) foi macerado em almofariz com $5 \mathrm{~mL}$ de água ultrafiltrada. Após a homogeneização, esse material foi submetido a uma centrifugação $(20.000 \mathrm{~g})$ por 30 minutos, coletando-se o sobrenadante e centrifugando-o $(20.000 \mathrm{~g})$ por mais 15 minutos. O sobrenadante resultante foi utilizado para as análises de nitrato.

O teor de nitrato foi determinado pelo método descrito por Cataldo et al. (1975). A cada alíquota de $200 \mathrm{~mL}$ foram adicionados $800 \mathrm{~mL}$ de ácido salicílico $5 \%$ dissolvido em ácido sulfúrico concentrado. Após um período de $20 \mathrm{~min}$, em temperatura ambiente, foram adicionados $19 \mathrm{~mL}$ de $\mathrm{NaOH} 2 \mathrm{~N}$. A absorbância da mistura resultante foi analisada a $410 \mathrm{~nm}$. Os ensaios foram repetidos duas vezes.

Quantificação dos pigmentos fotossintéticos - A análise do conteúdo de clorofila a, b e carotenóides foi realizada em duas amostras compostas de um grama de matéria fresca dos eixos caulinares provenientes de quarenta plantas por tratamento, as quais foram maceradas com nitrogênio líquido sendo, em seguida, acrescentados $3 \mathrm{~mL}$ de acetona pura gelada. O macerado resultante foi filtrado em papel de filtro. A acetona pura foi sendo adicionada sobre o macerado restante no papel de filtro, até que atingisse o volume final de $50 \mathrm{~mL}$ de filtrado. Esse procedimento foi realizado no escuro. As absorbâncias das clorofilas a e b foram lidas em 662 e $645 \mathrm{~nm}$, respectivamente e a dos carotenóides, em $470 \mathrm{~nm}$. As concentrações dos pigmentos foram determinadas de acordo com as equações definidas em Lichtenthaler (1987).

Análise estatística - As médias foram calculadas e submetidas à análise de variância, sendo comparadas pelo teste de Tukey em nível de 5\% de probabilidade (Gomes 1985). 


\section{Resultados e Discussão}

O método de clonagem utilizado nesta pesquisa produziu cerca de 50 novas plantas a partir de uma planta-matriz, em um ano de cultivo in vitro na ausência de reguladores de crescimento. Sabe-se que o aparecimento de variações é bastante diminuído quando se evita o emprego de substâncias reguladoras do crescimento vegetal (Pierik 1987, Zaffari et al. 2002, Zhao et al. 2005, Joyce et al. 2003). Em comparação à utilização de plantas obtidas a partir de sementes, o emprego de plantas clonadas para estudos fisiológicos diminui a variabilidade de respostas, pois não há influência da variação genética existente entre as plantas analisadas (Burr \& Tinus 1996). É particularmente interessante o uso de clones quando se empregam plantas com características interessantes (Mercier \& Nievola 2003), como é o caso desse cultivar do abacaxizeiro, muito utilizado na alimentação (Manica 1999).

Após 90 dias, as plantas originárias do desenvolvimento dos nós apresentaram um aspecto bem semelhante em termos de altura, número de folhas e coloração quando foram cultivadas em MS, MS/2 ou MS/5. Entretanto, em diluições maiores houve limitação do desenvolvimento de $A$. comosus observado nas figuras $2 \mathrm{E}(\mathrm{MS} / 60)$ e $2 \mathrm{~F}$ (MS/100) em relação às concentrações maiores dos macronutrientes (2A, 2B e 2C). Quanto à biomassa, quantidades equivalentes de massas fresca e seca da parte aérea foram encontradas quando as plantas foram cultivadas nos tratamentos MS, MS/2 e MS/5 (Figura 3A). Já em MS/10 houve uma redução de $40 \%$ nos valores desses parâmetros e de 75\% para MS/60 e MS/100 em comparação aos outros tratamentos. Para as raízes, obtiveram-se valores equivalentes de massas fresca e seca nos tratamentos MS, MS/2, MS/5 e MS/ 10 (Figura 3B). Em MS/60 e MS/100, houve uma redução de $90 \%$ nos valores desses parâmetros em relação aos outros tratamentos. Esses resultados indicaram que a diluição MS/5 teve os mesmos efeitos na promoção do crescimento in vitro do abacaxizeiro (parte aérea e sistema radicular) comparativamente aos meios MS e MS/2. Muitas bromélias nativas estão adaptadas a ambientes com pouca disponibilidade de nutrientes na natureza (Benzing 2000). É possível supor

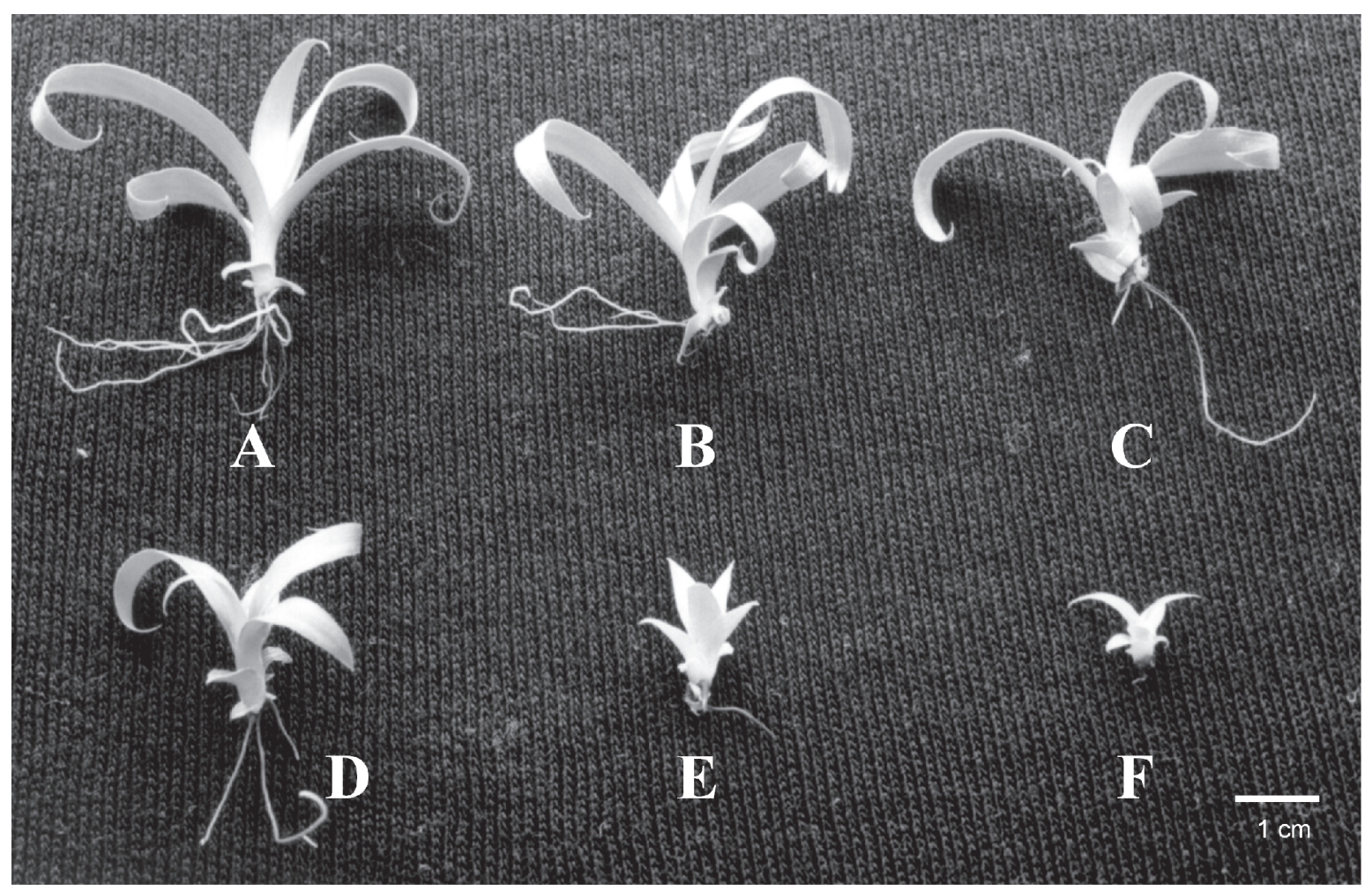

Figura 2. Plantas de Ananas comosus variedade Smooth Cayenne cultivadas in vitro por três meses em meio de Murashige \& Skoog (1962) (A), e nas diferentes diluições dos macronutrientes desse meio: MS/2 (B), MS/5 (C), MS/10 (D), MS/60 (E) e MS/100 (F). 

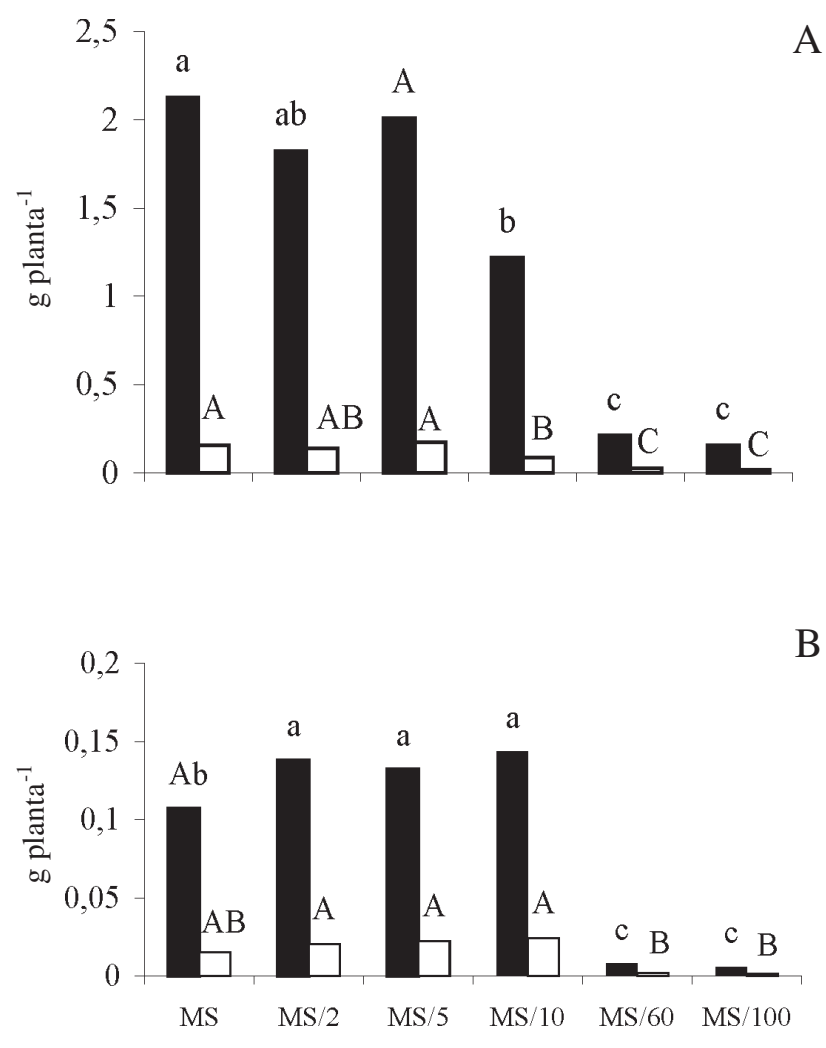

Figura 3. Massa fresca $\square$ e massa seca $\square$ do eixo caulinar (A) e das raízes (B) de plantas de Ananas comosus variedade Smooth Cayenne cultivadas in vitro em diferentes diluições do meio de Murashige \& Skoog (1962) (MS) após 90 dias de cultivo. Médias $(\mathrm{n}=10)$ acompanhadas por letras diferentes, minúsculas para a quantidade de massa fresca e maiúsculas para a quantidade de massa seca, diferem significativamente pelo teste de Tukey com $5 \%$ de probabilidade.

que o mesmo ocorra com o cultivar Smooth Cayenne.

Os teores de nitrato dos eixos caulinares foram maiores nas plantas cultivadas em MS, decrescendo $50 \%$ em MS/2, a $90 \%$ em MS/5 até não ser mais detectável a partir da diluição MS/60 (Figura 4). O abacaxizeiro tem sido considerado uma planta que pode acumular grandes quantidades de nitrato (Nievola $\&$ Mercier 2001). Experimentos realizados com essa espécie mostraram que plantas transferidas do meio MS para outro que não continha nitrogênio, onde permaneceram por 30 dias, apresentavam ainda uma certa quantidade endógena de nitrato (Tamaki 2003). Outras espécies, entretanto, como a orquídea Catasetum fimbriatum, não acumulam esse íon (Majerowicz et al. 2000). A concentração de nitrato fornecida na diluição MS/5 foi suficiente para promover o crescimento do abacaxizeiro, tendo em vista os resultados de massa fresca e seca obtidos nesse tratamento. É importante destacar que o teor de nitrogênio presente nessa diluição $(12 \mathrm{mM})$ se aproxima daquela contida na formulação do meio Knudson (1946) (16 mM), o qual é bastante utilizado para cultivo de bromélias em geral (Mercier \& Kerbauy 1997).

Quanto aos resultados de clorofila $a+b$ e carotenóides, não houve diferença significativa entre os tratamentos MS, MS/2 e MS/5 (Figura 5). As análises desses dados indicam que a quantidade absorvida e assimilada de nitrogênio, a partir do meio $\mathrm{MS} / 5$, foi suficiente para o desenvolvimento normal das plantas, como o obtido em MS. Ou seja, a quantidade de nitrogênio no meio MS original poderia estar além das necessidades nutricionais do clone de Ananas comosus analisado nesta pesquisa, promovendo um acúmulo de nitrato nos tecidos das plantas mantidas nessa condição. Já na diluição MS/5, a quantidade de nitrogênio fornecida seria suficiente para o desenvolvimento do abacaxizeiro. A partir da diluição MS/10, já se observou um comprometimento do crescimento, refletindo-se também na diminuição de $50 \%$ nos teores dos pigmentos (clorofila e carotenóides). Houve um comprometimento do desenvolvimento ainda maior em MS/60 e MS/100. Os teores de clorofila são normalmente empregados como fornecedores de uma estimativa do conteúdo de nitrogênio total da planta (Majerowicz et al. 2000). Segundo Netto et al. (2002), variações no conteúdo total de clorofila e carotenóides são bons indicadores do estresse em plantas. De acordo com Majerowicz et al. (2002), que avaliaram a eficiência do uso do nitrogênio em Zea mays, o teor foliar de pigmentos fotossintéticos foi suficiente para diagnosticar

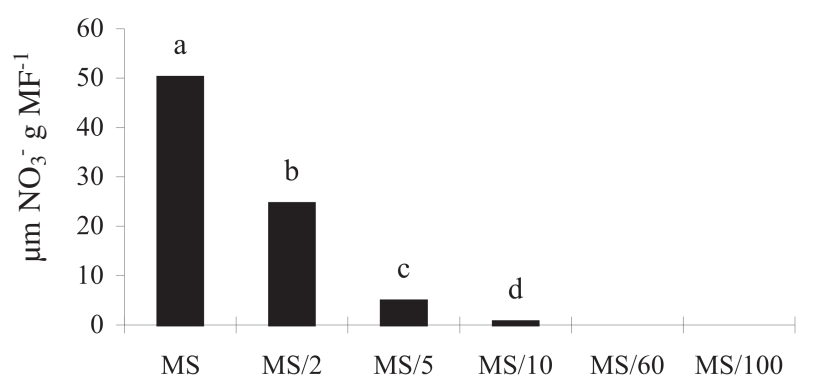

Figura 4. Teores endógenos de nitrato presentes nos eixos caulinares de plantas de Ananas comosus variedade Smooth Cayenne cultivadas in vitro por 90 dias em diferentes diluições do meio de Muraghige \& Skoog (1962). Médias $(n=40)$ acompanhadas por letras distintas diferem significativamente pelo teste de Tukey com 5\% de probabilidade. 


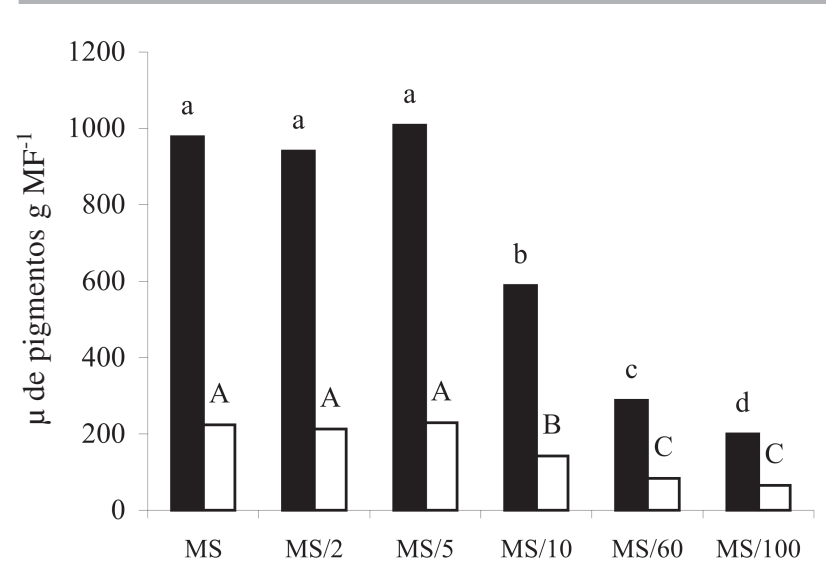

Figura 5. Concentração de pigmentos (clorofila $a+b \quad \boldsymbol{e}$ carotenóides $\square$ ) presentes nos eixos caulinares de plantas de Ananas comosus variedade Smooth Cayenne cultivadas in vitro por 90 dias em diferentes diluições do meio de Muraghige \& Skoog (1962). Médias $(n=40)$ acompanhadas por letras distintas, minúsculas para conteúdo de clorofila e maiúsculas para conteúdo de carotenóides, diferem significativamente pelo teste de Tukey com $5 \%$ de probabilidade.

diferenças no estado nutricional das plantas em função da quantidade de nitrogênio, de maneira semelhante ao observado neste trabalho com abacaxizeiro.

Embora a diluição do meio MS envolva também o decréscimo da concentração de outros macronutrientes, além do nitrogênio, Kanashiro (2005) verificou que esse nutriente é o principal fator limitante para o crescimento das bromélias. Os resultados deste trabalho sugerem que o abacaxizeiro do cultivar Smooth Cayenne pode ser cultivado in vitro na diluição $\mathrm{MS} / 5$, sem apresentar diferenças significativas em relação ao desenvolvimento das plantas cultivadas no meio MS completo, possibilitando uma redução de custos, o que é bastante desejável em laboratórios de micropropagação.

\section{Agradecimentos}

As autoras agradecem o auxílio financeiro obtido junto à FAPESP (processo 99/2660-9) e as bolsas de doutorado concedidas pelo CNPq a Vívian Tamaki (processo 142410/98-5) e pela CAPES a Catarina Carvalho Nievola.

\section{Literatura citada}

Argenta, G., Silva, P.R.F. \& Bortolini, C.G. 2001. Clorofila na folha como indicador do nível de nitrogênio em cereais. Ciência Rural 31: 715-722.
Argenta, G., Silva, P.R.F. \& Sangoi, L. 2004. Leaf relative chlorophyll content as an indicator parameter to predict nitrogen fertilization in maize. Ciência Rural 34: 1379-1387.

Barboza, S.B.S.C., Caldas, L.S. \& Souza, L.A.C. 2004. Micropropagação do híbrido PexSC-52 e da cultivar Smooth Cayenne de abacaxizeiro. Pesquisa Agropecuária Brasileira 39: 725-733.

Benzing, D. 2000. Bromeliaceae - Profile of an adaptive radiation. Cambridge University Press, Cambridge.

Burr, K.E. \& Tinus, R.W. 1996. Use of clones increases the power of physiological experiments on coastal Douglas-fir. Physiologia Plantarum 96: 458-466.

Caldas, L.S., Haridasan, P. \& Ferreira, M.E. 1998. Meios nutritivos. In: A.C. Torres, L.S. Caldas \& J.A. Buso (eds.). Cultura de Tecidos e Transformação Genética de Plantas. EMBRAPA-SPI / EMBRAPA-CNPH, Brasília, v. 1, pp. 87-132.

Canto, A.M.M.E., Souza, F.V.D., Costa, M.A.C., Souza,A.S., Ledo, C.A.S. \& Cabral, J.R.S. 2004. Conservação in vitro de germoplasma de abacaxi tratado com paclobutrazol. Pesquisa Agropecuária Brasileira 39: 717-720.

Cataldo, D.A., Haroon, M., Schrader, L.E. \& Youngs, V.L. 1975. Rapid colorimetric determination of nitrate in plant tissue by nitration of salicylic acid. Communications of Soil Science and Plant Annals 6: 71-80.

Devi, Y.S., Mujib, A. \& Kundu, S.C. 1997. Efficient regenerative potential from long term culture of pineapple. Phytomorphology 47: 255-259.

DeWald, M.G., Moore, G.A., Sherman, W.B. \& Evans, M.H. 1988. Production of pineapple plants in vitro. Plant Cell Reports 7: 535-537.

Gomes, F.P. 1985. A estatística moderna na pesquisa agropecuária. Associação Brasileira para Pesquisa da Potassa e do Fosfato (Potafos), Piracicaba.

Grossi, F. 2000. Aspectos da nutrição nitrogenada in vitro e atividade da redutase de nitrato em uma espécie de bromélia. Tese de Doutorado, Centro de Energia Nuclear na Agricultura, Universidade de São Paulo, São Paulo.

Guerra, M.P., Dal Vesco, L.L., Pescador, R., Schuelter, A.R. \& Nodari, R.O. 1999. Estabelecimento de um protocolo regenerativo para a micropropagação do abacaxizeiro. Pesquisa Agropecuária Brasileira 34: 1557-1563.

Hirimburegama, K. \& Wijesinghe L.P.J. 1992. In vitro growth of Ananas comosus L. Merr (pineapple) shoot apices on different media. Acta Horticulturae 319: 203-208.

Joyce, S.M., Cassells, A.C. \& Jain, M. 2003. Stress and aberrant phenotypes in in vitro culture. Plant Cell, Tissue and Organ Culture 74: 103-121. 
Kanashiro, S. 2005. Nitrogênio, Fósforo, Potássio, Cálcio e o crescimento de plântulas de Aechmea blanchetiana (BAKER) L. B. Smith in vitro. Tese de Doutorado, Escola Superior de Agricultura "Luiz de Queiroz", Universidade de São Paulo, Piracicaba.

Kiss, E., Kiss, J., Gyulai, G. \& Heszky, L.E. 1995. A novel method for rapid micropropagation of pineapple. HortScience 30: 127-129.

Knudson, L. 1946. A new nutrient solution for germination of orchid seed. American Orchid Society Bulletin 15: 214-217.

Lichtenthaler, H.K. 1987. Chlorophylls and carotenoids: pigments of photosynthetic biomembranes. In: L. Packer \& R. Douce (eds.). Methods in enzymology. Academic Press, London, v. 148, pp. 350-382.

Macedo, C.E.C., Silva, M.G., Nóbrega, F.S., Martins, C.P., Barroso, P.A.V. \& Alloufa, M.A.I. 2003. Concentrações de ANA e BAP na micropropagação de abacaxizeiro L. Merril (Ananas comosus) e no cultivo hidropônico das plântulas obtidas in vitro. Revista Brasileira de Fruticultura 25: 501-504.

Majerowicz, N., Kerbauy, G.B., Nievola, C.C. \& Suzuki, R.M. 2000. Growth and nitrogen metabolism of Catasetum fimbriatum (Orchidaceae) grown with different nitrogen sources. Environmental and Experimental Botany 44: 195-2006.

Majerowicz, N., Pereira, J.M.S., Médici, L.O., Bison, O., Pereira, M.B. \& Santos Júnior, U.M. 2002. Estudo da eficiência de uso do nitrogênio em variedades locais e melhoradas de milho. Revista Brasileira de Botânica 25: 129-136.

Manica, I. 1999. Fruticultura tropical: 5. Abacaxi. Cinco Continentes, Porto Alegre.

Margarido, S.M.F. 1991. Abacaxi: “'O rei dos frutos”. Coleção Brasil Agrícola, Ed. Ícone, São Paulo.

Mathews, V.H., \& Rangan, T.S. 1979. Multiple plantlets in lateral bud and leaf explant in vitro cultures of pineapple. Scientia Horticulturae 11: 319-328.

Mercier, H. \& Kerbauy, G.B. 1992. In vitro multiplication of Vriesea fosteriana. Plant Cell, Tissue and Organ Culture 30: 247-249.

Mercier, H. \& Kerbauy, G.B. 1994. In vitro culture of Vriesea hieroglyphica, an endangered bromeliad from the brazilian Atlantic Forest. Journal of the Bromeliad Society 44: 120-124.

Mercier, H. \& Kerbauy, G.B. 1997. Micropropagation of Ornamental Bromeliads (Bromeliaceae). Biotechnology in Agriculture and Forestry 40: 43-57.
Mercier, H. \& Nievola, C.C. 2003. Obtenção de bromélias in vitro como estratégia de preservação. Vidália 1: 57-62.

Murashige, T. \& Skoog, F. 1962. A revised medium for rapid growth and bioassays with tobacco tissue cultures. Physiologia Plantarum 15: 473-497.

Netto, A.T., Campostrini, E., Oliveira, J.G. \& Yamanishi, O.K. 2002. Portable chlorophyll meter for the quantification of photosynthetic pigments, nitrogen and the possible use for assessment of the photochemical process in Carica papaya L. Brazilian Journal Plant Physiology 14: 203-210.

Nievola, C.C. 1997. Influência da nutrição nitrogenada sobre a atividade de enzimas do metabolismo do nitrogênio em bromélias cultivadas in vitro. Dissertação de Mestrado, Instituto de Biociências, Universidade de São Paulo, São Paulo.

Nievola, C.C. \& Mercier, H. 2001. Variações diurnas da atividade in vivo da redutase do nitrato em abacaxizeiro (Ananas comosus (L.) Merr. - Bromeliaceae). Revista Brasileira de Botânica 24: 295-301.

Nievola, C.C., Mercier, H. \& Majerowicz, N. 2001. Uréia: uma possível fonte de nitrogênio orgânico para as bromélias com tanque. Bromélia 6: 44-48.

Pickens, K.A., Affolter, J.M. \& Wetzstein, H.Y. 2003. Enhanced seed germination and seedling growth of Tillandsia eizii in vitro. HortScience 38: 101-104.

Pierik, R.L.M. 1987. In vitro culture of higher plants. Martinus Nijhoff Pyblishers, Dordrecht.

Rangan, T. S. 1984. Pineapple. In: P.V.Amirato, D.A. Evans, W.R. Sharp \& Y. Yamada (eds.). Handbook of Plant Cell Culture. Macmillan Pub. Co, New York, v. 3, pp. 373-382.

Tamaki, V. 2003. Metabolismo nitrogenado e sinalização entre raiz e parte aérea em plantas de Ananas comosus cultivadas in vitro. Tese de Doutorado, Universidade de São Paulo, São Paulo.

Vinterhalter, B. \& Vinterhalter, D. 1994. True-to-the type in vitro propagation of Aechmea fasciata Baker. Scientia Horticulturae 57: 253-263.

Zaffari, G.R., Peres, L.E.P., Teacenco, F.A. \& Kerbauy, G.B. 2002. Indole-3-acetic acid metabolism in normal and dwarf micropropagated banana plants (Musa spp. AAA). Brazilian Journal of Plant Physiology 14: 211-217.

Zepeda, C. \& Sagawa, Y. 1981. In vitro propagation of pineapple. HortScience 16: 495.

Zhao, Y., Grout, B.W.W. \& Roberts, A.V. 2005. Abnormal chromosomes and DNA content in micropropagated rhubarb (Rheum rhaponticum L.) PC49. Plant Cell, Tissue and Organ Culture 83: 335-338. 